\title{
CURADURÍAS PARTICIPATIVAS Y VINCULACIÓN TERRITORIAL: EL PROYECTO 'MIRADA DE BARRIO' DEL MUSEO DE LA SOLIDARIDAD SALVADOR ALLENDE DE CHILE
}

\author{
Participatory curatorial practice and territorial link: 'Mirada de barrio' project of the Museo de la \\ Solidaridad Salvador Allende of Chile
}

\author{
Tomás Peters ${ }^{\mathrm{I}}$ \\ ${ }^{\mathrm{I}}$ Instituto de la Comunicación e Imagen, Universidad de Chile, Chile. \\ tpeters@uchile.cl
}

\section{RESUMEN}

Este artículo expone las estrategias investigativas y participativas realizadas en el proyecto Mirada de Barrio implementado por el Museo de la Solidaridad Salvador Allende (MSSA) para vincularse con su territorio, el barrio República de Santiago de Chile. Además de discutir el surgimiento y problemática de la nueva museología y la museología crítica, se discuten los elementos teóricos de la investigación-acción y las curadurías participativas. Posteriormente, se describe la trayectoria del proyecto Mirada de Barrio y la exposición Haciendo Barrio realizada en el museo en 2019. El artículo finaliza con los resultados de un estudio cuantitativo aplicado antes y después de la implementación del proyecto (2017 y 2019), donde se analizan los principales cambios en las percepciones de los vecinos tanto sobre su entorno barrial como del MSSA.

PALABRAS CLAVE: curadurías participativas; museo; territorio; patrimonio barrial; investigación-acción.

\section{ABSTRACT}

This article shows the investigative and participatory strategies implemented in the Mirada de Barrio project by the Museo de la Solidaridad Salvador Allende (MSSA), in order to establish a link with its territory, the República neighborhood in Santiago, Chile. In addition to discussing the rise and problematic of the new museology and critical museology, it examines theoretical elements of the action research and participatory curatorial practice. Later, this article describes the trajectory of the Mirada de Barrio project and the exhibition Haciendo Barrio in the museum in 2019. It finishes with the results of a quantitative survey implemented before and after the project (2017 and 2019): it shows the main changes in the perceptions of the neighbors about the neighborhood as well as the MSSA.

KEYWORDS: participatory curatorial practice; museum; territory; heritage neighborhood; action research.

Fecha de Recepción
2020-04-27

\begin{tabular}{|r|}
\hline Fecha de Evaluación \\
\hline 2020-06-II \\
\hline
\end{tabular}

Fecha de Aceptación $2020-06-30$

${ }^{1}$ Este trabajo es parte del Proyecto Fondecyt de Postdoctorado No 3180346: "Participación y consumo cultural en Chile en el siglo XXI: prácticas emergentes, nuevas desigualdades y redefiniciones teóricoculturales". 


\section{INTRODUCCIÓN}

Los museos han experimentado, en las últimas décadas, una serie de transformaciones en sus lógicas organizativas y estrategias discursivas. No solo han debido afrontar una acelerada complejización organizacional y funcional, sino también una demanda pública y social enfocada en criterios de participación cultural y acceso. Luego de medio siglo de reflexiones sobre el rol del museo en la sociedad, en la actualidad somos testigos de instituciones museales cada vez más preocupadas por sus públicos, comunidades y territorios. Sumado a su rol patrimonial, educativo e investigativo, estos espacios han adoptado medidas de acción destinadas a integrar y reflexionar las interrogantes de su entorno. Es decir, escuchar e interpretar las voces, deseos, preocupaciones, experiencias e imaginarios de los territorios donde se sitúan.

Estas nuevas lógicas operativas -transferidas desde la nueva museología y la museología crítica- han generado cambios sustantivos en la forma de pensar el rol de los museos en la sociedad. Sin embargo, implementar esos procesos no ha sido sencillo. En América Latina y, en especial en Chile, estos modelos de trabajo han tenido cierta acogida a nivel discursivo, aunque no sin dificultades en su implementación real. Los territorios y las comunidades siguen siendo un desafío que los museos han debido enfrentar tanto en sus planes de gestión, curaduría, planificación y autorreflexión.

El presente artículo se propone reflexionar sobre estos problemas y ampliar las preguntas sobre el mismo. A partir del proyecto Mirada de Barrio del Museo de la Solidaridad Salvador Allende (MSSA), este artículo expone las estrategias investigativas y participativas realizadas para vincular el museo con el barrio República de la ciudad de Santiago de Chile. El proyecto tuvo como objetivo desarrollar, a través de un proceso de investigación-acción y en conjunto con estrategias de participación-curadurial, un diagnóstico y valorización del patrimonio material e inmaterial del Barrio República. Bajo ese propósito, este artículo busca abordar cómo se producen los procesos de interrelación entre territorio, comunidad, patrimonio y museo, y evalúa cómo esas acciones modificaron las percepciones de los vecinos antes y después de la implementación del proyecto Mirada de Barrio.

El artículo se divide en cinco secciones. En la primera, se aborda el surgimiento y problemática de la nueva museología y la museología crítica. Al hacerlo, se busca contextualizar cómo los museos se han conectado con las nociones de participación, comunidad y espacio deliberativo. Posteriormente, y a partir de elementos teóricos de la investigación-acción y las 
curadurías participativas, el artículo reflexiona sobre el rol que ambas cumplen en la formación de diálogos comunes entre museo y territorio. En la tercera sección, se describe el proyecto Mirada de Barrio del MSSA implementado durante los años 2017 y 2019. A través de la descripción y reflexión de sus componentes, el artículo profundiza sobre sus procedimientos y decisiones. La cuarta sección expone los resultados de un estudio cuantitativo aplicado antes y después de la implementación del proyecto. En ella se presentan los principales cambios en las percepciones de los vecinos tanto sobre su entorno barrial como del MSSA. Finalmente, se ofrecen algunas conclusiones y dimensiones de análisis para pensar la relación entre museo, territorio y sociedad.

\section{LA (NUEVA) MUSEOLOGÍA (CRÍTICA): DESPLAZAMIENTOS E INTERRUPCIONES EN LA INSTITUCION MUSEO}

Los museos son instituciones históricas complejas. Desde su origen, se les ha exigido cumplir funciones de protección y reforzamiento de los patrimonios nacionales -y globales-, así como también definir métodos de trabajo para su conservación y circulación simbólica. Como tales, pueden ser comprendidos como una estructura de soporte del poder político (Gray, 2015). Pero, al mismo tiempo, también son depositarios de fragmentos históricos del pasado que permiten pensar el presente e interrogarse sobre el futuro. Son múltiples las teorías que se han escrito sobre la función del museo en la sociedad (Bennett, 1995; Knell et al, 2007; Simmons, 2016). Ellos corren en paralelo con las transformaciones de la sociedad y no pueden comprenderse sin las lógicas cambiantes de la producción económica, la circulación global de bienes simbólicos y las diversas formas de apropiación y uso de ellos en determinados contextos.

Los museos surgen gracias a las grandes colecciones de objetos y obras de arte de las realezas europeas, así como también de los depósitos históricos de la iglesia medieval y las nuevas burguesías (Jiménez-Blanco, 20I4). Esos "gabinetes de curiosidades" sirvieron tanto como recursos diferenciadores entre ciudades como entre castas sociales (Bennett, 1995). Esas primeras acumulaciones y registros de formas histórico-simbólicas, atesorados en salones o espacios específicos, estaban restringidas para gran parte de la población. Es solo a partir de los siglos XVII y XVIII con el auge de las grandes ciudades y el florecimiento de la sociabilidad urbana -por ende, con la necesidad de administrar los tiempos y cuerpos de los ciudadanos-, cuando la institución museo emerge como un lugar público (Bennett, 1995). Sin invitación ni adscripción alguna, estos visitantes pudieron acceder a un mundo simbólico infinito caracterizado por objetos de todas las latitudes. Sin embargo, el acceso universal no fue inmediato. Hasta mediados del siglo XX, los 
museos siguieron sirviendo a los poseedores históricos de los medios económicos, culturales y simbólicos de apreciación de estos (Selwood, 20I8).

Los museos se fueron conformando como los administradores de códigos excluyentes y generadores de diferenciación social (Bourdieu y Darbel, 2004). Sin embargo, esto no podía durar por mucho tiempo. A mediados del siglo XX y bajo los nuevos paradigmas de la democratización cultural -especialmente en Francia-, los museos debieron enfrentar una serie de cuestionamientos e interrogantes (Cuenca, 2014). Desde la década de 1960, los museos tuvieron que experimentar un giro social que se materializaría con la emergencia de los ecomuseos (Eidelman et. al, 20I4). En ese entonces, los museos debieron dar un giro en sus políticas al avanzar en una nueva forma de pensar la relación entre los visitantes (espectadores, públicos, audiencias, observadores) y las colecciones disponibles en su interior. Con los acuerdos adquiridos en la "Mesa de Santiago de Chile" en 1972, la museología tomó un rumbo cada vez más radical y en contraposición a la noción conservadora de los museos. Desde esa convención de UNESCO, el museo debía ser "integral" y al servicio de la sociedad y su desarrollo, dando paso a la "nueva museología" (Alonso, 1999; Díaz, 2002).

Desde la creación en Lisboa del "Movimiento Internacional para una Nueva Museología" en 1985, este movimiento ha logrado avances significativos en la forma de establecer lógicas colaborativas y dialógicas entre museo y territorio. Al priorizar la participación social antes que la sacralización del objeto, esta nueva corriente buscó reconocer a la colectividad como un agente activo y dinámico. Es decir, como un recurso capaz de articular procesos sociales en relación con los museos.

Aun cuando estos planteamientos han mantenido un reconocimiento generalizado en la comunidad museológica, lo cierto es que su implementación real tuvo más resistencias que acogidas. Como ha señalado Díaz (2002), hasta finales del siglo XX los museos seguían siendo tradicionales en sus fundamentos. Sin embargo, al comenzar el siglo XXI, una nueva ola de pensamiento museológico emergió: la "museología crítica" (Lorente y Almazán, 2003; Santacana y Hernández, 2006). Radicalizando los postulados de la nueva museología, esta tendencia se caracterizó por comprender a los museos como zonas de conflicto e interacción crítica entre los diversos agentes involucrados (directores, curadores, burócratas, coleccionistas, públicos, comunidades).

Para lo museología crítica no bastaba hacer partícipe a la comunidad. Su propósito era comprender al museo como un lugar de interrogantes, controversias y aprendizajes mutuos. Los 
profesionales de los museos, los visitantes y comunidades son comprendidos como "creadores" de conocimientos. Como han señalado Ceballos y Macaroff (2015), estas nuevas propuestas no son comprensibles sin reconocer los procesos generales de la pedagogía crítica, la producción artística contemporánea y la mediación artística. De hecho, las comunidades de aprendizaje en los museos son instancias que han buscado construir una ciudadanía crítica en base a la participación cultural, pero en relación con las nuevas prácticas artísticas contemporáneas. Gracias al surgimiento de nuevas prácticas artísticas que se enfocaron en los públicos y en su labor participativa -arte relacional, arte público, proyectos artísticos comunitarios y participativos (Bishop, 2012)-, los museos debieron reflexionar sobre su propio operar y comenzaron a establecer, en sus planes y programas, nuevas lógicas de trabajo con sus públicos y/o visitantes. Bajo este escenario, los museos han tenido que adaptarse con nuevas estrategias didácticas, herramientas interactivas innovadoras y métodos de trabajo como el aprendizaje activo. Esto implicó pensar el museo desde un abordaje crítico, donde la creación e interpretación de las obras se co-construyen entre diversos agentes y desde diversas maneras de observación y experimentación. En la medida en que los visitantes o la comunidad dialoga con el museo, este reevalúa su misión y valores y, de esa forma, define los contenidos como coproducidos (Simon, 2010).

Como señala Mairesse (2013), la colaboración entre museo y comunidad tiene relación con la figura del "don" de Marcel Mauss: dar, recibir y devolver. En la medida en que los museos mantienen relaciones de intercambios de objetos $-\mathrm{o}$, en este caso, de ideas, historias y colaboraciones- con un grupo o comunidad, entonces se establece una relación de dependencia y se alimentan los vínculos personales y comunitarios. Bajo ese paradigma, y como afirma Jennifer Barrett (2012), los museos se describen en la actualidad como sitios de deliberación pública. Comprendidos como esferas críticas de debate público, los museos hoy en día no cumplen el rol histórico de depósito de reliquias o patrimonios nacionales e internacionales, sino que son espacios donde se discute lo público y lo común. Aun cuando existen voces críticas sobre el rendimiento de esos propósitos en el presente (Kurnitzky, 2013), los museos cumplen una función crítico-cultural y política. Y en Iberoamérica estos debates no han carecido de atención (Castilla, 20ıO; León, 20I2; Sabaté y Gort, 2012; Pinochet, 2016). 


\section{CURADURÍAS PARTICIPATIVAS: ENTRE EL HACER CONJUNTO Y PENSAR LA DIFERENCIA}

Si bien tanto la nueva museología como la museología crítica han generado cambios significativos en las formas de pensar los museos, no es posible identificar metodologías específicas o esquemas puros de trabajo según esos postulados. Por el contrario, el museo hoy comparte elementos de la (nueva) museología (crítica) así como también de la museología histórica (Sabaté y Gort, 20I2). Lo que es evidente es que los modelos de trabajo en los museos son cada vez más híbridos y se alimentan de variadas fuentes y modelos, tantos actuales como tradicionales. Sin embargo, enmarcados en lógicas de gestión burocrática, los museos contemporáneos se han visto interpelados a demostrar su eficiencia y eficacia a partir de estadísticas de visitante y/o de popularidad, así como también sus capacidades para vincularse con sus territorios, lo que les ha exigido elaborar planes para demostrar su impacto social y cultural.

Desde la década de 1980 se ha logrado demostrar que participar en programas artísticos de espacios culturales locales genera cambios no solo en las trayectorias biográficas de los participantes, sino que también revitaliza los barrios y genera nuevas sinergias entre ellos y su comunidad (Belfiore y Bennett, 2008). Esto ha sido especialmente evidente en el caso de los museos de arte (Kelly, 2006; Watson, 2007; Bienkowski, 2016). En ellos se producen una serie de interacciones sociales y experiencias significativas tanto entre sus visitantes (o públicos) así como también con sus comunidades.

Como han señalado Knell, MacLeod y Watson (2007), es importante reconocer que históricamente los museos han sido configurados y definidos discursivamente en directa relación con los materiales de conocimiento (objetos, documentos, piezas históricas, nombres) oficialmente reconocidos y legitimados a través de decisiones curaduriales definidas por "autoridades" (críticos, directivos, consejos académicos). Sin embargo, al igual que en los laboratorios (Bennett, 2005), los museos pueden dar forma y hacer cambios en las maneras de pensar la historia y los patrimonios culturales de un barrio o territorio. Es ahí, por ende, donde se reconoce el valor social del museo: gracias a que existen vínculos, reconocimientos y conflictos entre las personas y los museos es que es posible cambiar las propias "curadurías". En este sentido, al no existir líneas expositivas (artísticas, históricas, científicas, etcétera) incuestionables, hoy es posible redefinir y reinventar la misión de los museos contemporáneos en conjunto con las comunidades.

Aun cuando se ha afirmado la dificultad de esta tarea, existe un consenso transversal por destacar la necesidad de desarrollar procedimientos de investigación que contribuyan a 
profundizar y complejizar las formas de pensar el museo en su entorno social (Silverman, 20Io). En vistas de aquello, la investigación-acción ha surgido como una herramienta de análisis pertinente para entender y problematizar las dinámicas e interrelaciones entre museo y territorio. Según Villasante (2006), la investigación-acción participativa reconoce que los objetos que pretendemos investigar (colectivos, sectores, comunidades) tienen sus propias estrategias de vinculación con su entorno y muchas veces son conflictivas e hipercomplejas. Una investigación-acción desarrollada entre un museo y su entorno implica conocer y comprender, más que controlar.

A partir de la metodología de investigación-acción, en los últimos años han surgido modelos de trabajo que se han complementado con las técnicas curaduriales del arte contemporáneo (Evans, 20I4; Waller, 2016). Estas nuevas estrategias, que aquí podríamos denominar como de investigación-acción-curadurial, ofrecen un camino valioso de trabajo. La idea de vincular comunidades en los museos a través de procesos curaduriales ha logrado un impulso importante en los últimos años, especialmente en museos de carácter antropológico y científico (Deliss, 20I4).

Como se ha observado en otras experiencias que vinculan curaduría participativa y exposición museal (Klarich, 2014), los beneficios de estos modelos no son simplemente lograr integrar distintos grupos de interés en la elaboración de un guión expositivo, sino que, sobre todo, ponen a discutir diversos discursos y problemáticas contemporáneas en diálogo con objetos o manifestaciones artísticas del pasado y del presente. Este formato curadurial-participativo permite entonces ofrecer nuevas lógicas de discusión tanto al interior de los museos (en los guiones definidos institucionalmente) como en su entorno y territorio (en las actividades situadas y dinámicas de la comunidad). En síntesis, la relación dinámica entre investigación, acción (participación) y curaduría permite elaborar un trabajo en línea con las tendencias de la museología crítica, al buscar establecer una lógica participativa y dialógica entre museo, comunidad/territorio y contenidos (obras, artefactos, fotografías, etcétera).

A partir de este planteamiento de trabajo, durante los años 2017 y 2019 se diseñó e implementó el proyecto Mirada de Barrio en el Museo de la Solidaridad Salvador Allende de Santiago de Chile. Su propósito fue elaborar estrategias investigativas y participativas que ayudaran a vincular el museo con el barrio República de la ciudad de Santiago de Chile (Merino, 2014). El proyecto tuvo como objetivo desarrollar, a través de un proceso de investigación-accióncuradurial, un diagnóstico y valorización del patrimonio material e inmaterial (vivencias, relatos, objetos e historias de vecinos) del Barrio República. Para implementarlo, el proyecto contempló 
una serie de acciones y utilizó una estrategia de recolección de información a partir de observaciones participantes, encuestas, entrevistas en profundidad, registros fotográficos y audiovisuales, conversaciones grupales, ejercicios de valoración patrimonial (material e inmaterial) y un "mapeo participativo".

\section{MIRADA DE BARRIO: CON LOS OJOS EN REPÚBLICA}

Los inicios del MSSA se remontan a principios de r97r en Santiago de Chile, cuando surge la idea de promover en los círculos artísticos de América y Europa la donación de obras de arte que permitieran al gobierno de la Unidad Popular crear un museo para el pueblo de Chile. La convicción y apoyo del presidente Salvador Allende fue clave, ya que, al comprender la dimensión histórica de esta iniciativa, posibilitó las condiciones institucionales para desarrollar este ambicioso y utópico proyecto, que se mantiene vigente hasta la actualidad.

No es coincidencia que el MSSA surgiera casi en paralelo con la "Mesa Redonda" de Santiago de Chile de 1972. Además de discutir sobre la importancia y el desarrollo de los museos en el mundo contemporáneo, en la mesa se elaboraron los postulados y recomendaciones sobre cómo hacer que los museos se transformaran en lugares al servicio de la comunidad. En sus casi 50 años de historia, el MSSA no solo se ha propuesto facilitar el acceso, difusión e investigación del patrimonio artístico legado en apoyo al proyecto político-cultural de la Unidad Popular, sino también lograr que ese conocimiento esté disponible para la sociedad en su conjunto.

Debido al golpe de Estado del ir de septiembre de 1973, el MSSA debió vivir una serie de procesos de expatriación y censura, así como también de resguardo en diversas bodegas privadas. Al retornar la democracia, el MSSA vivió un proceso de reconfiguración y reformulación, y se alojó en diversas instalaciones en Santiago. Sin embargo, desde el 2005, el MSSA se instala definitivamente en el palacio Heiremans, ubicado en el barrio República de Santiago.

En los últimos io años, el museo no solo ha logrado un fortalecimiento de su misión histórica, sino que también ha intencionado su trabajo con el territorio y los vecinos. De esta forma, nació el proyecto Mirada de Barrio, el cual consistió en una investigación-acción y una curaduría participativa que buscó, por una parte, rescatar los relatos, experiencias e historias de vecinos que constituyen el patrimonio inmaterial del Barrio República, y, por otra, cómo este dialoga con el patrimonio artístico del MSSA. 
El proyecto Mirada de Barrio se compuso de dos fases. La primera de ella consistió en la elaboración, por una parte, de una discusión interna sobre los conceptos de museología crítica, territorio y curadurías participativas - presentado en la primera parte de este artículo-, así como también en la organización y ejecución de una serie de encuentros-talleres con los vecinos del Barrio República para reconstruir, describir y problematizar el patrimonio material e inmaterial del Barrio República en relación con el MSSA. A partir de estas acciones, el proyecto dio paso a su segunda fase que consistió en desarrollar entre los vecinos y el Área Públicos del MSSA un guión curadurial que derivó en la exposición Haciendo Barrio durante septiembre de 2018 y febrero de 2019 (García, 2019).

\section{PRIMERA PARTE. LOS CONTACTOS: INTRODUCCIÓN Y PRODUCCIÓN DEL PROYECTO MIRADA DE BARRIO}

Entre marzo de 2017 y agosto de 20I8, el proyecto Mirada de Barrio realizó una serie de encuentrostalleres entre los profesionales del MSSA y los vecinos del barrio República. En ellos participaron residentes, dirigentes vecinales, autoridades barriales y contactos previos con otras organizaciones del sector. En el primer encuentro se logró reunir a cerca de 15 vecinos y vecinas, y sirvió para presentar los objetivos del proyecto. Al realizar este ejercicio de reconocimientos mutuos, se buscó establecer un primer nivel de acuerdos sobre las expectativas recíprocas de los agentes involucrados (del museo, público, comunidad, territorio). Al mismo tiempo, los participantes generaron un mapeo colectivo, localizándose en el barrio de manera física y simbólica, marcando sus lugares de encuentro y sus espacios en disputa para explorar, en sus historias, los legados culturales y narrativos que han permanecido y cambiado en el tiempo.

En los siguientes encuentros, los intercambios comunes entre el museo y los vecinos se concentraron en establecer diálogos comunes a partir de objetos, fotografías, recuerdos o artefactos sensibles que les permitiera establecer vínculos emocionales con el Barrio República. El objetivo de esta petición estaba dado en lograr construir relatos biográficos con el territorio y, sobre todo, en relación con las estrategias y técnicas de la investigación-acción-curadurial. En la medida en que los vecinos podían enseñar y/o compartir sus recuerdos o retazos de vida con otros vecinos $-y$, por cierto, con los profesionales del MSSA-, se podría lograr una recolección de datos para ir pensando el relato curadurial-participativo. Los diálogos fueron registrados y posteriormente analizados por el equipo de investigación y fue posible establecer cuatro ejes de análisis señalados por los vecinos con respecto al barrio: "memoria", "lugares de encuentro", "sonido" y "conflictos y disputas". 
Según la lógica propuesta en la investigación-acción-curaduríal, esta clasificación analítica cumplía un rol fundamental en el proyecto (ver Esquema i). El objetivo era establecer un esquema de sentido que permitiera desplegar elementos históricos del Barrio República, así como también sus conflictos y tensiones, lugares de encuentro y de nostalgia. Pero, sobre todo, tenía como propósito establecer un camino común de trabajo entre los vecinos, el territorio y el MSSA.

El primer eje de análisis fue el de "Historia/Memoria". En él se integran los sedimentos históricos del Barrio República, así como también cómo ha sido su evolución arquitectónica y urbanística. Concebido como un espacio dinámico, híbrido y en permanente mutación, los vecinos desplegaron un imaginario centrado en la importancia de las áreas verdes (como la plaza Manuel Rodríguez), los lugares de encuentro (como los negocios y tiendas históricas), las instancias de socialización (como el MSSA), las edificaciones históricas (las casonas de Avenida República, Remodelación República), etcétera. Este eje se propuso reforzar el valor patrimonial del barrio, pero, al mismo tiempo, tenía como objetivo gatillar en los vecinos un relato vinculado a sus trayectorias biográficas.

El eje de "contraposición" fue denominado como de "Silencios/Sonidos". Al tener un fuerte valor histórico, el Barrio República no ha estado escindido de los momentos más oscuros del Chile reciente. Un grupo de vecinos sintió interés en dialogar sobre cómo la dictadura militar había producido ciertos silencios o, directamente, lógicas del miedo en el barrio. Algunos de ellos recordaron cómo en ciertas casas no era posible sacarse fotos o mantenerse más tiempo de lo normal, debido a la presencia de la policía secreta del régimen dictatorial. Al seleccionar algunas casas o esquinas, los vecinos reforzaron la figura del silencio como un recurso históricamente existente y biográficamente marcador. Ahora bien, en el mismo eje surgió también la figura de sonidos, pero desde una perspectiva contemporánea. Si el silencio se vinculaba a la historia del barrio, el sonido -entendido como ruido- se manifestaba como un elemento del presente. Los vecinos identificaron esquinas y calles concretas como abandonadas y caracterizadas por el ruido y la molestia constante de los actuales usuarios del barrio.

Este último punto nos vincula con el eje "Disputas". Otro grupo de vecinos incorporó los conflictos y tensiones del Barrio República. Quizá este eje fue el que logró mayor atención, debido, entre otras cosas, porque se podían tratar problemáticas comunes y en relación con seguridad y cuidado barrial. Entre los temas recurrentes de conversación en este eje se pueden mencionar: la basura en el barrio, los estudiantes universitarios y sus prácticas de "no-respeto" (alcohol en vía pública, desinterés por peatones adultos mayores, destrucción de inmobiliario, peleas nocturnas), 
crecimiento exponencial de inmigración y hacinamiento en condiciones de riesgo, crecimiento inmobiliario inorgánico, etcétera. Este eje podría ser reconocido como el de mayor preocupación por parte de los vecinos. De hecho, podrían denominarse instancias catárticas del proyecto Mirada de Barrio.

Esquema r: Ejes de análisis del Barrio República a partir de relatos, diálogos e imaginarios de sus vecinos

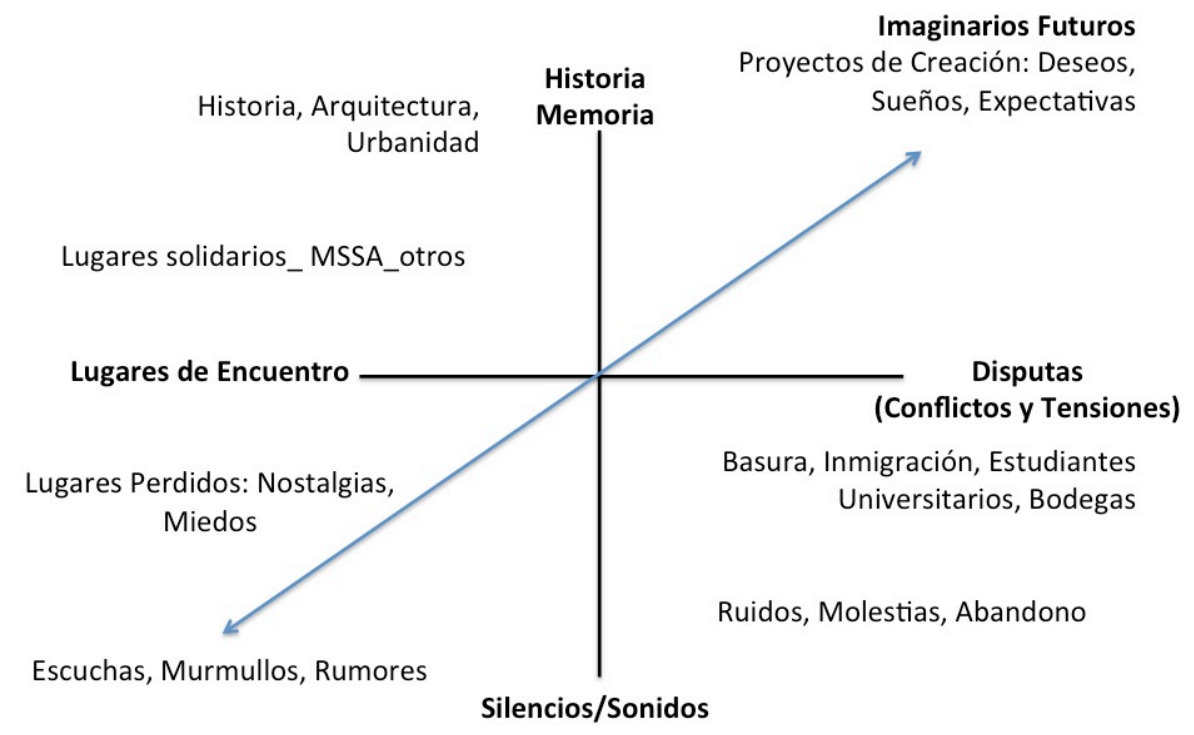

Fuente: Elaboración propia a partir de diálogos con vecinos Barrio República y el MSSA.

Finalmente, el eje "Lugares de Encuentro" sirvió para establecer no solo lugares con valor patrimonial, sino sobre todo con carácter social-afectivo. Al estar ligado con el eje de "Historia/Memoria", este cuadrante se comprende como instancias que recuerdan experiencias de sociabilidad y que construyen una historia común. A diferencia de los otros ejes, este mantiene un elemento de memoria viva, dispuesta para abrir nuevos horizontes y poner a distancia los lugares nostálgicos o ya perdidos. Según los vecinos, el mantener esa nostalgia de los "buenos tiempos" permite soñar otros nuevos. De ahí entonces es posible tomar un hilo de oportunidades. Es decir, pensar en conjunto otros caminos posibles de desarrollo barrial.

Como es posible observar en el Esquema I, el esquema de análisis se complementa con los "Imaginarios Futuros". Este eje buscó plantear preguntas tales como: ¿Cuáles son los deseos, sueños y expectativas de los vecinos sobre el Barrio República? ¿Qué es posible de realizar en conjunto? ¿Cómo se puede, desde la historia del barrio, crear una historia nueva, diferente y común? Este eje 
de imaginarios futuros buscaba establecer un horizonte de expectativas común que sirviera como referencia posible para el futuro.

\section{SEGUNDA PARTE. HACIENDO BARRIO: LA EXPOSICIÓN FINAL}

La investigación-acción-curadurial definida para Haciendo Barrio requirió tanto de conceptos como de procedimientos de creación de insumos (obras, instalaciones, intervenciones, publicaciones). Durante la última etapa del proyecto se realizaron entre el equipo del MSSA y las/os vecinos de República nuevos talleres, encuentros e intervenciones urbanas que dieron paso al montaje e instalación de la exposición. En estas actividades se conformaron equipos de trabajo cuyos resultados fueron presentados en seis salas del museo: Sala I, con los talleres de "Escritura y publicación experimental", "Intervención fotográfica" y "Textil comunitario"; Sala II con los talleres de "Arte Postal"; Sala III, con el documental Mirada de Barrio; Sala IV descrita como "de experiencias"; Sala V donde se exhibió la metodología de trabajo del proyecto; y Sala VI donde se expusieron los trabajos de mapeo colectivo del barrio. ${ }^{2}$ En su conjunto, Haciendo Barrio fue una sintesis integrada de todas las experiencias, saberes, afectos, narraciones y escrituras surgidas durante los años del proyecto entre el MSSA y los/as habitantes -tanto permanentes como temporales- del barrio República. Es, además, una exposición que se construye en base a las dinámicas arriba identificadas y que emergen entre la memoria histórica, los lugares de encuentro, los sonidos y silencios del territorio, y los conflictos y tensiones que disputan el presente. Pero, al mismo tiempo, es una exposición que genera imaginarios futuros.

La Sala I de Haciendo Barrio contiene todos estos elementos. En ella se plasmaron diversas co-creaciones que ofrecieron micro-narraciones sobre el territorio, la memoria y la historia del barrio. En esta sala se utilizaron, además, mapas y planos del barrio, así como también reflexiones sobre el pasado, el presente y el futuro. También se trazaron elementos biográficos (lazos vecinales, familiares, afectivos y emocionales). En suma, estos recursos expositivos permitieron recordar, escuchar, relatar e imaginar las intensidades de los recorridos y transformaciones del barrio.

Una de las piezas fundamentales de esta sala fue "Textil comunitario" (3,36 x 4,15 mts, técnica mixta), creado colectivamente en el taller "Puntada a puntada: reconstruyendo mi barrio". En ella se delineó el mapa del Bario República a partir de cortes y confecciones de trazos textiles que simbolizaban episodios biográficos, residuos culturales y metáforas sensibles de las/os vecinas/os. Retomando la tradición patrimonial de las arpilleras, en el textil no solo se establecen

\footnotetext{
${ }^{2}$ Para una selección fotográfica de la exposición, véase https://cutt.ly/GRgojWh (Abril, 2020).
} 
los trazados cuadrangulares de las calles del barrio, sino también sus sitios y espacios simbólicos. Al estar desplegado como un mural tejido, las miradas del espectador pueden situarse en cada una de las esquinas e hitos destacados, e identificar distintas capas emotivas: lugares de tortura y violaciones a derechos humanos; hogares e instancias de intimidad familiar; espacios de reunión y convivencia; parques y áreas recreativas; negocios y lugares de intercambio; entre otros. En cada tejido se establecen vínculos territoriales y afectivos que entrelazan recuerdos y percepciones en curso. Las puntadas en el textil son como escrituras que narran los hechos y delinean los deseos: definen los miedos y establecen nuevas expectativas. En suma, el "Textil comunitario" retoma la metáfora de reestablecer el tejido social: tanto en su creación como en exhibición, esta obra transforma los imaginarios del barrio y produce un deseo de inmersión territorial nueva, inédita, inminente.

Por su parte, el conjunto de fotografías intervenidas complementa las visiones históricas del barrio República. A través del coloreado, bordado y collage sobre fotografías impresas, estas obras buscan re-situar los entramados familiares, situacionales y emocionales cristalizados en la fotografía. Desplegadas en una estructura-andamiaje especialmente creada para la exposición, estas fotografías intervenidas adquieren una condición de contemporaneidad. Con cada coloración y zurcido -de lanas e hilos de color rojo- se establece un nuevo encuadre: uno caracterizado por situar una selección fotográfica del pasado en un presente continuo. Cada fotografía posee una relación biográfica con las/os vecinas/os: pero con esa interrupción/incorporación lumínica y superficial exterior (color y trazo textil) en el hoy, esa imagen-recuerdo deviene en un espacio/momento recuperado y actualizado. Esas fotografías intervenidas son, para las/os vecinos que las han aportado, un trazo biográfico que se ilumina y destaca en el aquí y ahora.

Finalmente, las publicaciones experimentales (cuadernos en miniatura, fanzines y libroobjetos) y las escrituras creativas exhibidas en la sala I recurren al formato escritural/objetual como recurso reflexivo del Barrio República. Situadas en mesones y paredes, estas superficies narrativas hacen eco de los relatos, memorias, imaginarios y disputas que ha producido y produce el habitar urbano del barrio. En estos textos culturales se relatan vivencias, escuchas, silencios, nostalgias, miedos, murmullos, molestias, abandonos, sueños y expectativas. Las menciones abarcan desde las fachadas y espacios históricos, hasta los habitantes en curso: comerciantes, estudiantes, allegados, vendedores ambulantes, migrantes. También esos libros-objetos describen poéticas del territorio: hablan del amor por la arquitectura e historia del barrio, y de sus descubrimientos biográficos con/en él. En síntesis, estas plataformas editoriales de dimensiones variables hablan y describen los 
cinco ejes del barrio república: memoria, silencios/sonidos, lugares de encuentro, disputas (conflictos y tensiones) e imaginarios futuros.

La Sala II fue una sumatoria entre visualidad, escritura y desplazamiento imaginario. Durante enero y julio de 20I8, el proyecto realizó dos talleres de "Arte Postal" para vecinos/as entre 5 y I2 años. Dispensadas en una estructura de bloques/murales, estas postales reunieron imágenes, dibujos y trazos visuales con textos, poemas y declaraciones de principios. En ellas se observaban desde relatos barriales hasta exigencias de cuidado animal; desde la valorización de las áreas verdes hasta el reconocimiento arquitectónico del barrio; desde exigencias de espacio y nuevos servicios públicos hasta propuestas urbanas para niños. Pensadas como cartas visuales-narrativas móviles, las postales de este taller tuvieron un principio clave: la creación visual y la narración del territorio desde la voz infantil.

Situada como una sala de cine -con sillas de formas y diseños dispares, debido a que cada vecino/a prestó una durante el tiempo que duró la exposición-, la Sala III proyectó el documental Mirada de Barrio. Compuesto por los registros del proceso de investigación-acción-curadurial de este proyecto, este documental no solo monta un relato experiencial de las/os vecinos sobre el Barrio República, sino también los principales hitos de los encuentros, talleres, reuniones y acciones que derivaron en la exposición Haciendo Barrio. Durante el mismo se entrelazan relatos históricos, percepciones presentes y expectativas del barrio. Así como en toda la exposición, nuevamente emergen los ejes clave tematizados: la memoria histórica, los lugares de encuentro, los silencios y sonidos, los conflictos y tensiones, y los proyectos, deseos y sueños de las/os vecinos. Lo valioso del documental es su condición de registro histórico: en su montaje se ven los rostros, tonalidades y miradas de las/os protagonistas en cuestión.

La Sala IV fue comprendida y diseñada como un espacio presente continuo. Frente a la pregunta ¿Cómo vives tu bario?, las/os visitantes a la exposición podían utilizar todos los recursos materiales, visuales, imaginarios, poéticos- utilizados en el proyecto para responderla. Bajo el propósito de pensar y hacer el barrio, esta sala buscaba aportar tanto a la creación colectiva como a la vida comunitaria. Para ello, el plan era disponer este espacio para experimentar y contribuir en la creación de una pieza textil, una postal, un relato o una intervención fotográfica, tal como las obras dispuestas en la Sala I. En otros términos, este espacio fue pensado como un laboratorio/taller para las/os vecinos -o transeúntes- del Barrio República que no participaron a lo largo del proyecto, pero que quisieran aportar desde sus propias experiencias, relatos, narraciones, sueños e imaginarios. 
La quinta Sala puede ser descrita como el marco metodológico de Mirada de Barrio. En ella se plasmó el modelo de trabajo realizado para la concreción de la exposición en sí y que fue denominado como "Itinerario de procesos y creaciones con las vecinas y vecinos del Barrio República”. En él se sitúa al MSSA como un espacio articulador y abierto a su entorno: es decir, como un lugar pensado para interactuar, movilizar y activar el territorio donde está emplazado. Para ello, el diagrama explica cómo se establecieron los primeros contactos con las/os vecinos, las estrategias de generación de confianza y cooperación mutua, y el reconocimiento de los distintos agentes actuantes del Barrio República por parte del museo. Frente a este diagrama se exhibieron dos hitos del proyecto: por una parte, las encuestas aplicadas por el equipo de investigadores para conocer la percepción/imaginario de las/os vecinos sobre el MSSA al inicio del proyecto y, por otra, uno de los resultados de un mapeo corporal y colectivo del barrio realizado por las vecinas y vecinos.

Finalmente, la sala VI acogió el trabajo de mapeo colectivo realizado por el equipo de artistas argentinos "Iconoclasistas". A partir de narraciones, saberes, sensibilidades y experiencias cotidianas, los mapeos colectivos buscan interrumpir los trazados oficiales del territorio. Reconociendo las diferencias entre el mapa y el territorio, el trabajo de Iconoclasistas buscó establecer un nuevo orden de sentido de los barrios/espacios comunes. Y lo hicieron justamente a través del reconocimiento de los problemas, deseos, disputas, silencios y especulaciones imaginarias de las/os vecinos con respecto a sus barrios. Esta sala recopiló y puso en presencia los trabajos realizados por el equipo en las esquinas, plazas y fachadas del Barrio República.

Haciendo Barrio fue una exposición que puso en obra las narraciones históricas, presentes y futuras de las/os vecinos del Barrio República. Pero, al mismo tiempo, estableció un vínculo emergente entre ellos y el MSSA. Y este era, justamente, el objetivo del proyecto inicial. Sin embargo, surge la pregunta si, luego de todo este trabajo común, ha cambiado la percepción de las/os vecinos con respecto al MSSA. En otros términos, ¿se han generado nuevos imaginarios entre las/os vecinos sobre el rol, función y misión del MSSA en el Barrio República?

\section{ELABORACIÓN DE DIAGNÓSTICO: ENCUESTA BARRIAL}

Como se ha señalado, este proyecto no solo buscó redefinir las lógicas de convivencia del MSSA con el Barrio República, sino también reconocer imaginarios, percepciones y sensibilidades que las/os vecinas/os tenían con respecto al museo. Con ese propósito, el proyecto creó una encuesta destinada a conocer esas lecturas mutuas en el tiempo en dos periodos: antes de la implementación de los talleres y encuentros barriales (abril de 20r7) y luego con la exposición Haciendo Barrio (abril de 
2019). La ejecución analítica de esta encuesta-instrumento en "dos tiempos" buscó determinar las transformaciones o redefiniciones de las percepciones de las vecinas y los vecinos luego del plan de trabajo barrial del MSSA. Luego del trabajo de vinculación territorial, Mirada de Barrio se propuso identificar dos dimensiones críticas: por una parte, explorar las percepciones y apreciaciones de los vecinos y las vecinas sobre su barrio y, por otra, sus miradas y apreciaciones sobre el MSSA.

La ejecución del instrumento-encuesta se pensó como un ejercicio participativo. Tanto en su elaboración como en su aplicación fueron parte una serie de vecinas/os, investigadoras/es, trabajadoras/es del museo y estudiantes. La idea de Mirada de Barrio fue establecer una experiencia de levantamiento de información colaborativa, abierta y voluntaria. Tanto en la primera aplicación en abril de 2017, como en su versión de abril de 2019, se aplicó el mismo instrumento-encuesta y se realizó el mismo procedimiento: luego de capacitar a las/os voluntarias/os en un desayuno de bienvenida, se les encargó por equipo una cuadra del Barrio República. En total fueron distribuidas 22 cuadras y participaron cerca de 20 encuestadores/as en cada sesión. A cada uno/a se le asignó un punto de inicio y, siguiendo los punteros del reloj, consultaba en cada hogar la posibilidad de ser encuestado. Cada uno/a debía realizar, al menos, zo encuestas. Si completaba todos los hogares y no había logrado cumplir la meta, entonces se disponía de la posibilidad de encuestar a un/a vecino/a que se movilizara a pie por el barrio. El criterio de selección fue estricto si era o no vecino y/o trabajador del Barrio República. ${ }^{3}$

\section{RESULTADOS: PERCEPCIÓN DEL BARRIO REPÚBLICA}

Al ser consultados sobre si les gustaba su barrio, en ambos años se observa un porcentaje mayoritario de respuesta afirmativa (96\% en 2017; 94\% en 2019). Al revisar los aspectos específicos que les gustaban a las/os vecinas/os de su entorno, en el Gráfico I se evidencian diferencias entre ambas mediciones. En la medición de 2019 se observa una mayor valoración sobre las "casas y edificios (arquitectura)" del barrio, así como también de su "ubicación y conectividad", con respecto a la medición anterior. Sin embargo, entre 2017 y 2019 hay una disminución en la valoración que las/os vecinas/os hacen sobre las "calles y plazas", "tiendas y locales", sus "habitantes" y la "historia del barrio". En el aspecto de "forma de vida del barrio" casi no hay diferencias entre ambas mediciones.

\footnotetext{
3 Según datos oficiales, en el Barrio República circulan diariamente, entre población flotante (estudiantes y trabajadores) y residentes, cerca de 200.000 personas. En la primera sesión de 2017, se lograron realizar 3i6 encuestas; en 2019 , 376. Estadísticamente, la muestra posee un 95\% de confianza y un margen de error de $\pm 5 \%$. En la versión de 2017 la distribución por sexo fue equilibrada en 50\%. Sin embargo, en la versión de 2019 la distribución fue de $46 \%$ femenino, $54 \%$ masculino. En ambas versiones, en promedio, los vecinos y trabajadores encuestados habían vivido o trabajado io años en el Barrio República. Al mismo tiempo, el promedio de edad de los/as encuestados/as de ambas sesiones fue de 40 años (y con una moda de 33 ).
} 


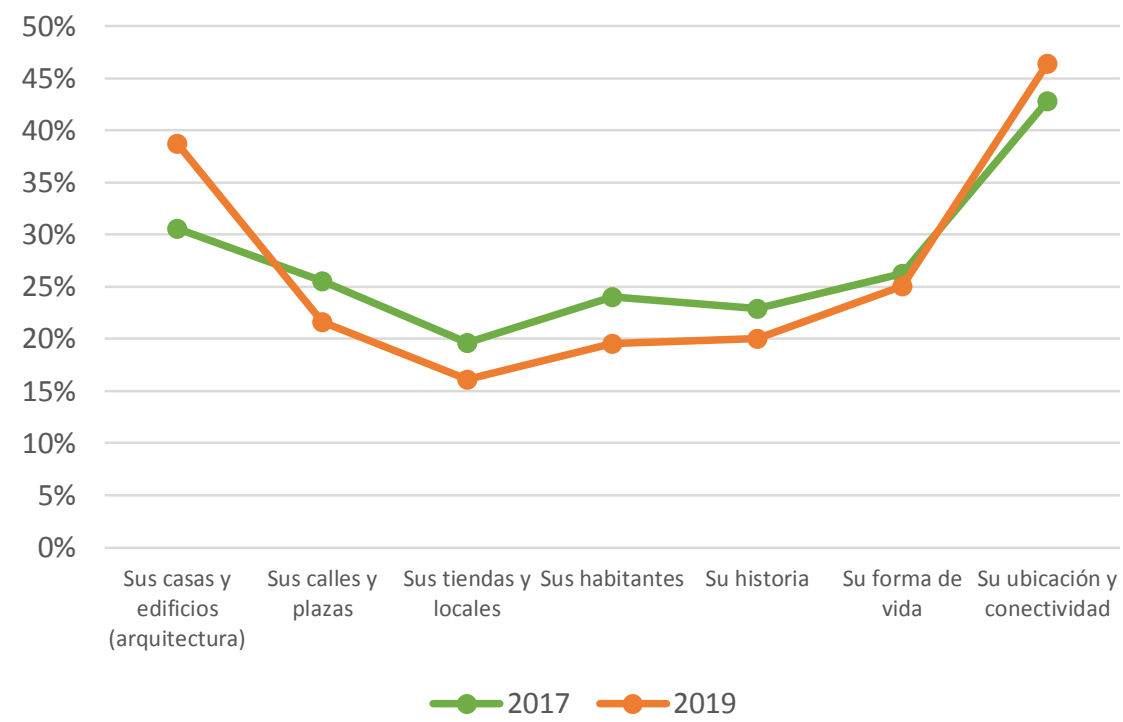

\section{Gráfico r: Percepción de las/os vecinas/os del Barrio República sobre su entorno (2017-2019) (Fuente:}

Encuesta para "Vecinos/Residentes" proyecto Mirada de Barrio versión 2017 y 2019, MSSA).

Según los datos, se observa una disminución en la valoración del barrio en la última medición. Al respecto, es interesante observar que las/os encuestadas/os de zorg que expresaron una valoración negativa afirman en sus respuestas abiertas que el barrio ha cambiado por la migración, la inseguridad y el vandalismo. Esta percepción de cambio se evidencia en otra de las preguntas del instrumento: en 2017, el 62\% de las/os vecinas/os señalaban que el barrio había cambiado en los últimos años. En la versión 2019, ese valor aumentó a un 71\%. Sin embargo, al preguntarles cómo describirían su barrio en una palabra, en ambas versiones los términos con mayor frecuencia fueron "Tranquilo", "Universitario" y "Bonito".

\section{RESULTADOS: PERCEPCIÓN DEL MSSA}

Frente a la consulta “qqué rol debería cumplir un museo en un barrio como este?”, las/os vecinas/os contestaron en 2017 las siguientes menciones (identificadas según mayor frecuencia): fomentar la cultura, contar la historia del barrio y educar. Y tres años más tarde, señalaron: contar la historia del barrio, resguardar su cultura, crear comunidad y educar.

En base a estos imaginarios del rol que debería cumplir un museo en su territorio, se indagó si las/os vecinas/os habían escuchado hablar del MSSA. En la versión 2017, la respuesta afirmativa fue de un $62 \%$, mientras que la de 2019 , un $60 \%$. De los que sí conocían el museo, en la primera versión un 43\% había entrado a ver sus exposiciones, mientras que en la última esta cifra fue de un $40 \%$. Al profundizar si las/os vecinas/os percibían que el MSSA era conocido por el resto de los residentes del barrio, en 2017 esta cifra fue de $28 \%$, mientras que en la de 2019 , el valor 
aumentó a un 34\%. Según estas cifras, la percepción de las/os vecinas/os sobre la presencia del MSSA en el barrio creció con respecto a la primera medición. Esta información se complementa con los resultados presentados en el Gráfico 2.

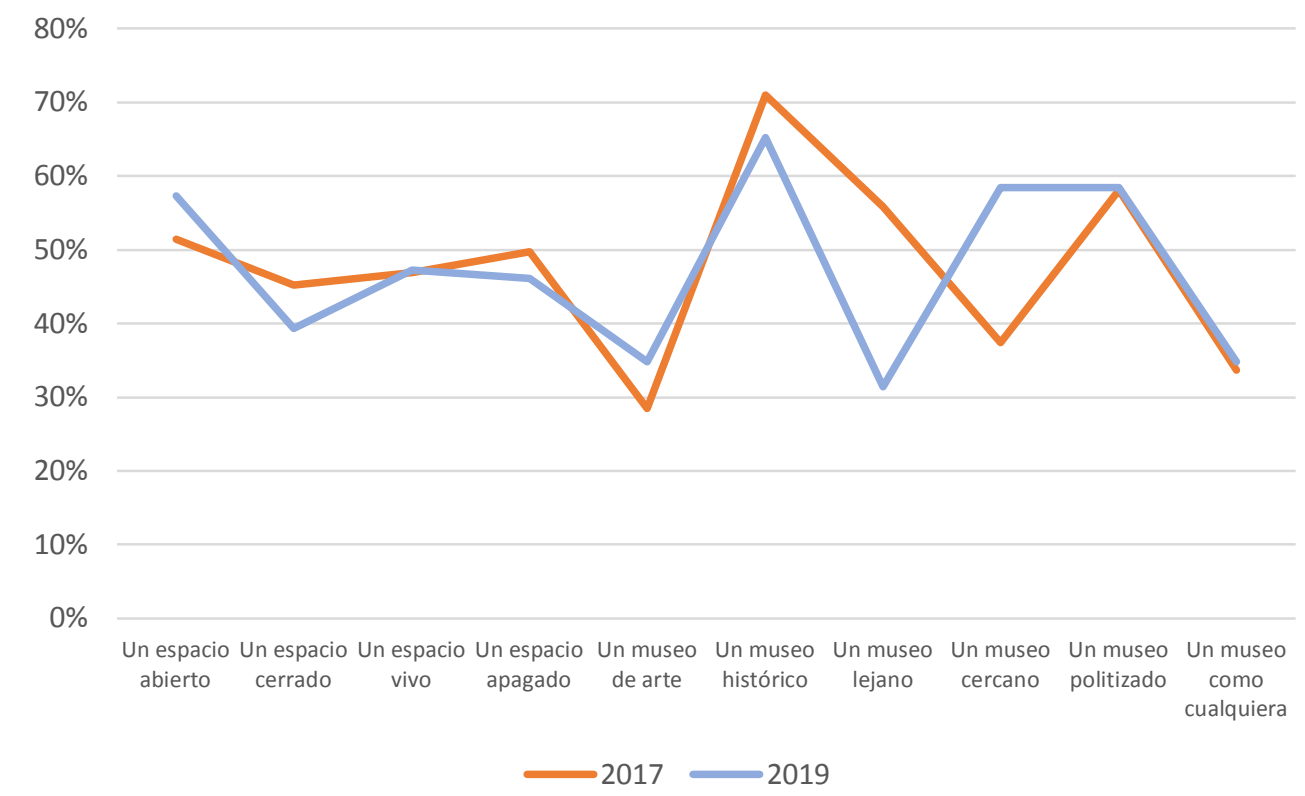

\section{Gráfico 2: Percepción de las/os vecinas/os del Barrio República sobre el MSSA (2017-2019) (Fuente: Encuesta para "Vecinos/Residentes" proyecto Mirada de Barrio versión 2017 y 2019, MSSA).}

Frente a los "descriptores de pares opuestos" definidos para ambas mediciones, es posible determinar que, luego del trabajo territorial del MSSA, se observa un cambio en las percepciones de las/os vecinas/os sobre el museo. Al consultarles si el MSSA es más bien un espacio cerrado o un espacio abierto, entre la medición 2017 y 2019 se evidencia un cambio favorable hacia percibir el museo como un espacio abierto. Con respecto a la percepción de si es un espacio más bien vivo o uno apagado, no se advierten cambios estadísticos significativos, salvo un cambio desfavorable de la opción de que el MSSA sea un espacio apagado. Entre las opciones de si el MSSA es más bien un museo de arte o uno histórico, se observa que, en la última medición de 2019, hay un aumento importante en el reconocimiento de que el MSSA es un museo de arte, aun cuando la mayoría de las/os entrevistadas/os lo reconocen como un museo histórico. Donde se observan las mayores diferencias estadísticas es entre el par museo lejano/museo cercano. Entre la medición de 2017 y 2019, se advierte una clara tendencia a percibir el MSSA como un museo cercano, revirtiéndose la tendencia anterior de considerarlo como un espacio lejano a las/os vecinas/os. Finalmente, no se observaron diferencias estadísticas entre el par museo politizado/museo como cualquiera. Entre 
ambas mediciones no varió la percepción de que el MSSA es un espacio reconocido por su condición histórico-política.

Finalmente, frente a la pregunta “¿qué le aporta el MSSA al Barrio República?”, las/os vecinas/os respondieron en ambas sesiones los mismos términos: cultura e historia.

Las cifras aquí desplegadas presentan algunas lecturas valiosas para pensar el efecto de Mirada de Barrio. En primer lugar, los barrios mutan y experimentan desplazamientos de sentido entre sus habitantes. Los paisajes arquitectónicos y urbanos sirven como escenarios de tensiones siempre en proceso, y el Barrio República es un buen ejemplo de ello. Como se observó en las mediciones de las percepciones de las/os vecinas/os sobre su territorio, las miradas han tendido a una valoración general favorable. Y, a pesar de las posiciones críticas sobre la migración y la delincuencia, el Barrio República es considerado como un espacio donde se vivencia y experimenta lo común: la belleza de sus paisajes y la tranquilidad del pasar.

Como se evidenció en las cifras, las intervenciones del MSSA en su territorio tuvieron efectos en los reconocimientos recíprocos. Aun cuando la asistencia al museo no aumentó con respecto a la medición de 2017, es clave constatar que la identificación general de las/os vecinas/os sobre el MSSA aumentó significativamente. Lo mismo ocurrió al revisar los atributos contrapuestos. Fue claro evidenciar que el museo se percibe como un espacio cercano y no lejano como antes. Lo mismo es posible de señalar al concebirlo como un espacio abierto y no cerrado, así como también al percibirlo cada vez más como un museo de arte (aunque la lectura de que es un museo histórico es mayoritaria). En suma, según la medición en "dos tiempos" es posible advertir que, a través de lecturas inductivas comunes, se produjo un giro en el imaginario que el Barrio República ha ido forjando sobre el MSSA. Hoy se comprende como un espacio distinto, más integrado al barrio y en relación con sus vecinos. Según estos resultados, el trabajo territorial de Museo de Barrio y las decisiones internas del MSSA al concebir el territorio como un agente de interés y valoración en su conformación organizacional, ha estrechado las distancias entre el museo y su territorio.

\section{CONCLUSIONES}

Los museos deben comprenderse por experimentar una complejización acelerada (Martineau, 2017): además de resguardar, conservar y exhibir el patrimonio visual-cultural de una sociedad, deben establecer vínculos con sus territorios y vecinas/os. Si antes los museos debían rendir sus resultados con organismos estatales o financistas, en la actualidad también lo hacen con sus comunidades. En 
suma, han establecido un "nuevo trato" con sus entornos que se caracteriza, muchas veces, por ser complejo y en permanente cruce de expectativas. Aun cuando esos puentes se han construido con un afán de colaboración y reciprocidad, lo cierto es que el uso de estos requiere de tiempo y negociaciones permanentes. Pero, sobre todo, se necesita establecer una relación de respeto/trabajo ético por el otro.

El MSSA es un museo de arte moderno y contemporáneo. En sus salas exhibe principalmente artes visuales y su andamiaje discursivo está en línea con las tendencias teóricas de vanguardia. Estos elementos no hacen sino complejizar la situación. Por un lado, el MSSA forma parte de las políticas artísticas del arte contemporáneo y muchas de sus energías (exposiciones, seminarios, ediciones) están puestas en su posicionamiento estratégico al interior del círculo del arte. Por el otro, el Barrio República es heterogéneo, en cambio permanente y con un patrimonio cultural en disputa. Al mismo tiempo, es un barrio con problemas variados, donde se entrecruzan demandas por seguridad, cuestionamientos a las universidades y sus usos de la vía pública, desconfianzas con las poblaciones migrantes, etcétera. Un museo no puede hacerse cargo de "catalizar todas las demandas" de las/os vecinos. Más bien, puede servir como un espacio que busca constituirse como una esfera pública, un lugar deliberativo de co-pertenencia. Y es en esa dirección donde apuntó Mirada de Barrio, proyecto que continúa su trabajo hasta el presente.

\section{REFERENCIAS}

Alonso Fernández, Luis. Introducción a la nueva museología. Madrid: Alianza Editorial, 1999. Impreso.

Barrett, Jennifer. Museums and the public sphere. Oxford: Wiley-Blackwell, 20I2. Impreso

Bennett, Tony. "Civic laboratories. Museums, cultural objecthood and the governance of the social". Cultural Studies, 19/5 (2005): 521-547

Bennett, Tony. The birth of the museum. History, theory, politics. London \& New York: Routledge, 1995. Impreso

Belfiore, Eleonora y Oliver Bennett. The Social Impact of the Arts: An Intellectual History. London: Palgrave Macmillan, 2008. Impreso.

Bienkowski, Piotr. No Longer Us and Them. How to change into a participatory museum and gallery. Learning from the Our Museum programme. Bristol: PHF, 20I6. Impreso. 
Bishop, Claire. Artificial Hells: Participatory Art and the Politics of Spectatorship. London: Verso, 2012. Impreso.

Bourdieu, Pierre y Alain Darbel. El amor al arte: los museos europeos y su público. Barcelona: Paidós, 2004. Impreso.

Castilla, Américo. (Eds.) El museo en escena. Política y cultura en América Latina. Buenos Aires: Paidós, 2010. Impreso.

Ceballos, Alejandro y Anihi Macaroff (Eds.). Contradecirse una misma. Museos y mediación educativa crítica. Experiencias y reflexiones desde las educadoras de la documenta 12. Quito: Fundación Museos de la Ciudad, 2015. Impreso.

Cuenca, Jaime. "La democratización cultural como antecedente del desarrollo de audiencias culturales". Quaderns d'animació i Educació Social, №ำ (2014).

Deliss, Clémentine "Curating Neighborhoods: Manifesto for the Post-Ethnographic Museum". Modern Painters, 26/8 (2014): 34-35.

Díaz, Ignacio. “¿Qué fue de la nueva museología? El caso de Quebec”. Revista Artigrama, I7 (2002): 493-516. Impreso.

Eidelman, Jacqueline et al. (Eds.). El museo y sus públicos. El visitante tiene la palabra. Barcelona: Ariel, 20I4. Impreso.

Evans, Catherine. "The Impact of the participatory, Visitor-Centered model on curatorial practice". Journal of Museum Education, 39/2 (2014): 152-161. Impreso.

García, Soledad. "Casa de experimentos: preguntas y transformaciones recientes del Museo de la Solidaridad Salvador Allende y su integración a la comunidad del Barrio República". Revista Poiésis, 20/33 (2019): 257-276. Online.

Gray, Clive. The politics of museums. London: Palgrave-Macmillan, 2015. Impreso.

Jiménez-Blanco, María. Una historia del museo en nueve conceptos. Madrid: Cátedra, 20r4. Impreso.

Kelly, Lynda. Measuring the impact of museums on their local community. New Roles and Missions of Museums: INTERCOM Symposium, Taipei, Taiwan R.O.C, 2006. 
Klarich, Elizabeth. "Crafting, community, and collaboration: Reflections on the Ethnographic Sala Project at the Pukara Lithic Museum, Peru". Museum Anthropology, 37/2 (2014): II8-I32. Impreso.

Knell, Simon, Susanne MacLeod y Sheila Watson (Eds.). Museum revolutions: How museums change and are changed. London \& New York: Taylor \& Francis Group, 2007. Impreso.

Kurnitzky, Horst. Museos en la sociedad del olvido. México: CONACULTA, 20I3. Impreso.

León, Aurora. El museo. Teoría, praxis y utopía. Madrid: Cuadernos Cátedra de Artes, 20I2. Impreso.

Lorente, Jesús Pedro y David Almazán (Eds.). Museología crítica y arte contemporáneo. Zaragoza: Prensas Universitarias de Zaragoza, 2003. Impreso.

Mairesse, François. El museo híbrido. Buenos Aires: Ariel, 2013. Impreso.

Martineau, Jonathan. "Culture in the age of acceleration, hypermodernity, and globalized temporalities". The Journal of Arts Management, Law, and Society, 47/4 (2017): 218-229. Impreso.

Merino, Roberto. Barrio República. Una crónica. Santiago, Chile: Editorial Universidad Diego Portales, 20I4. Impreso.

Padró, Carla. "Museología crítica como forma de reflexionar sobre los museos como zonas de conflicto e intercambio". En: Lorente, Jesús Pedro y Almazán, David (Eds.). Museología crítica y arte contemporáneo. Zaragoza: Prensas Universitarias de Zaragoza, 2003. Impreso.

Pinochet, Carla. Derivas críticas del museo en América Latina. México: Siglo XXI Editores, 2016. Impreso.

Sabaté, Miquel y Roser Gort. Museo y comunidad. Un museo para todos los públicos. Gijón: Ediciones Trea, 2012. Impreso.

Santacana, Joan y Francesc Hernández. Museología crítica. Gijón: Ediciones Trea, 20o6. Impreso.

Selwood, Sara. "Museums for the many? Rhetorical optimism and the failure of sustained political will at three London government-funded museums - then and now". Cultural Trends, 27/4 (2018): 270-295. Impreso. 
Sheppard, Beverly. "Do museums make a difference? Evaluating programs for social change". Curator, 43 (2000): 63-74.

Silverman, Lois. The Social Work of Museums. Oxon \& New York: Routledge, 2010. Impreso.

Simmons, John. Museums: a history. London: Rowman \& Littlefield, 2016. Impreso.

Simon, Nina. The participatory museum. Santa Cruz, California: Museum 2.0, 2010. Impreso.

Villasante, Tomás. "La socio-praxis: un acoplamiento de metodologías implicativas". En: Canales, Manuel (Ed.). Metodologías de Investigación Social. Introducción a los oficios. Santiago, Chile: Lom, 2006.

Waller, Laurie. "Curating actor-network theory: testing object-oriented sociology in the science museum". Museum and Society, I4/I (2016): 193-206.

Watson, Sheila. Museums and their Communities. Oxon \& New York: Routledge, 2007. Impreso. 